\title{
Preface to the Diamond Jubilee Issue on "Selected Topics in Iron and Steel and Their Processing toward the New Steel Age"
}

\author{
Ryuji UEMORI*
}

Editor-in-Chief, ISIJ International and Tetsu-to-Hagané

Professor, Research Center for Steel, Kyusyu University, 744 Motooka, Nishi-ku, Fukuoka, 819-0395 Japan.

ISIJ International has celebrated its 60th anniversary since the first publication owing to the substantial support from the contributors and others concerned. This journal has started with publications in 1961 as Tetsu-to-Hagané Overseas. After the period under the name of Transactions of the Iron and Steel Institute of Japan (1966 to 1988), it was renamed to the current ISIJ International (1989 to 2020). As a specialized journal on steel research, it has consistently included various contents from overall technologies relating to steel manufacturing processes to the forefront of steel physical metallurgy. It includes 14 academic fields: fundamentals of high temperature processes, ironmaking, steelmaking, casting and solidification, instrumentation, control and system engineering, chemical and physical analysis, forming processing and thermomechanical treatment, welding and joining, surface treatment and corrosion, transformations and microstructures, mechanical properties, physical properties, new materials and processes, and social and environmental engineering. As few other specialized journals in the world include such a wide range of steel technologies, considering the high quality of its articles, ISIJ International is regarded as a first-class steel-specialized journal. This success has been achieved through the efforts of numerous steel researchers who have contributed to the journal and support by the readers of the members of the Iron and Steel Institute of Japan who have been well versed in steel research. We would like to use this opportunity to formally express our gratitude to those who have been engaged in the publication of this journal.

This special issue is published in commemoration of its 60th anniversary with the title of "The Diamond Jubilee Issue: Selected Topics in Iron and Steel and Their Processing toward the New Steel Age" and has 37 articles in total from various fields including reviews, of which 28 are from Japan and 9 are from international contributors. Among the 37 articles, according to the field, 7 involve studies on ironmaking, 14 on steelmaking, 2 on analysis, 2 on environment, 2 on instrumentation and control, 4 on processing, and 6 on materials. Consequently, they cover almost all fields of steel research. We believe that this issue could deliver important and up-to-date information on steel research to the readers. As stated below, numerous interesting articles are included, which have focused on such important subjects in steel research that they may be considered standing aloof from the current research directions.

- Numerical investigation for the temperature depen-

\footnotetext{
* Corresponding author: E-mail: uemori@zaiko.kyusyu-u.ac.jp
}

dence of coke degradation by $\mathrm{CO}_{2}$ gasification reaction in a blast furnace

- Thermodynamic modeling of liquid steel

- Quantitative phase-field modeling and simulations of solidification microstructures

- Development of a shape meter employing the LED dot pattern projection method for a hot strip finishing mill

- Formulation of a generalized flow curve for $0.2 \%$ carbon steel under high-speed hot forming conditions by a regression method

- Control of core-shell type second phase formed via interrupted quenching and intercritical annealing in a medium manganese steel

- Limiting retained austenite decomposition in quenched and tempered steels: influences of rapid tempering and silicon

Additionally, this special issue includes congratulatory messages from the President and honorary members of the Iron and Steel Institute of Japan. We would like to express cordial thanks to all authors for their hearty congratulations and high expectations toward ISIJ International.

As aforementioned, ISIJ International has, as a specialized journal of steel research, covered a broad range of research, including basic research, applied research, development research, modeling, and simulation, from manufacturing processes to the characteristics of steel materials. At present, the readers include engineers all over the world who have been concerned with steel technologies, as well as steel researchers in Japan and abroad. We believe that ISIJ International plays an important role in continuously transmitting the excellent knowledge and information obtained from basic and applied steel researches to steel engineers worldwide and thus contributes to the realization of innovative technologies that could serve as the foundation of steel industry in the future. Moreover, it is essential for future steel industry to produce steels that are simultaneously environmentally friendly, highly efficient, and inexpensive. In this regard, it is necessary to significantly enhance steel technologies from existing levels. To this end, we aim to contribute to the development of the steel science leading to the achievement of such steel technologies.

Finally, the editorial committee have currently been making efforts to further improve the quality of ISIJ International as a steel-specialized journal. We will strive to make this journal increasingly attractive to major steel researchers. In particular, we sincerely hope that ISIJ International will serve as a place for young steel engineers to learn about a comprehensive picture of steel research. 